\title{
On the local time dependence of the penetration of solar wind-induced electric fields to the magnetic equator
}

\author{
M. C. Kelley and E. Dao \\ School of Electrical and Computer Engineering, Cornell University, Ithaca, NY, USA
}

Received: 1 October 2008 - Revised: 27 March 2009 - Accepted: 27 March 2009 - Published: 5 August 2009

\begin{abstract}
For a period of a few hours, the penetration of electric fields of solar wind origin is at its highest efficiency. In November 2003, five days of continuous vertical drift data were obtained at the Jicamarca Radio Observatory. Here we have isolated a range of frequencies centered at a few-hour period for a five-day period and have explored the local time dependence of the penetration, along with the time delay due to magnetospheric effects. We find that the latter ranges from 15 to $25 \mathrm{~min}$. For the local time dependence, we find that the period of anti-correlation is roughly from 21:00 to 04:00 LT, with positive correlation at other local times.
\end{abstract}

Keywords. Interplanetary physics (Cosmic rays) - Ionosphere (Equatorial ionosphere) - Magnetospheric physics (Solar wind-magnetosphere interactions)

\section{Introduction}

That the interplanetary electric field in the earth's frame of rest can penetrate very quickly deep into the inner magnetosphere and even to the magnetic equator has been recognized for 40 years (Nishida, 1968; Kelley et al., 1979). To first order, the direction of the prompt penetrating electric field (PPE) is the same as the y-component of the interplanetary electric field $\left(\mathrm{IEF}_{y}\right)$. That is, when the interplanetary magnetic field (IMF) has a southward component, $\mathrm{IEF}_{y}$ is positive (pointing dawn to dusk) and the PPE is east on the dayside and west at night, both pointing dawn to dusk. Likewise, when $\mathrm{IEF}_{y}$ is negative, the PPE points from dusk toward dawn. Examples of the former case were published by Kelley et al. (2003). During this event, $\mathrm{IEF}_{y}$ was positive and the eastward component of the daytime electric field measured

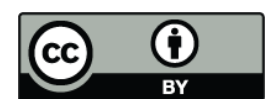

Correspondence to: M. C. Kelley (mikek@ece.cornell.edu) at the Jicamarca Radio Observatory correlated strongly positive. On 14 April 1978, the opposite case was evident. $\mathrm{IEF}_{y}$ went sharply negative and the zonal electric field at Millstone Hill, Arecibo, and Jicamarca all turned sharply dusk to dawn (Gonzales et al., 1983).

This relationship is quite an oversimplification, however. From modeling, it is known that the local time dependence of the nighttime conductivity pattern plays a role in the manner in which the field penetrates (Nopper and Carovillano, 1978). Recently, a major magnetic storm occurred on 8-11 November 2004 at a time when all of the upper atmospheric radars were operating (Kelley et al., 2009), providing coverage unmatched since the April 1978 event discussed above. Figure 1 compares the electric field measured at Jicamarca with the $\mathrm{IEF}_{y}$ divided by ten. A very high correlation (.85) existed from 19:00 UT on the 9th to 04:00 UT on the 10th. Then, although the $\operatorname{IEF}_{y}$ remained positive for several more hours, the Jicamarca field changed sign relative to the $\operatorname{IEF}_{y}$, beginning at about 23:00 local time (04:00 UT). This same change occurred at Arecibo, which is about one hour east of Jicamarca. This effect has been explained as a local time dependence of the PPE by Kelley and Retterer (2008). Here we investigate another unique data set obtained at Jicamarca in November 2003 to explore this local time effect of penetrating electric fields in more detail.

\section{Data presentation and discussion}

Ever since the pioneering work of Vasyliunas (1972), it has been known that the transfer function between the solar wind and the inner magnetosphere acts like a high pass filter with a breakpoint at a frequency corresponding to periods of 6 to $8 \mathrm{~h}$. Earle and Kelley (1987) and, more recently, Kelley et al. (2008) noted that the transfer function between the IEF and the equatorial field seems to have a weak resonance at a period of a few hours. Occasionally, the IEF displays long

Published by Copernicus Publications on behalf of the European Geosciences Union. 


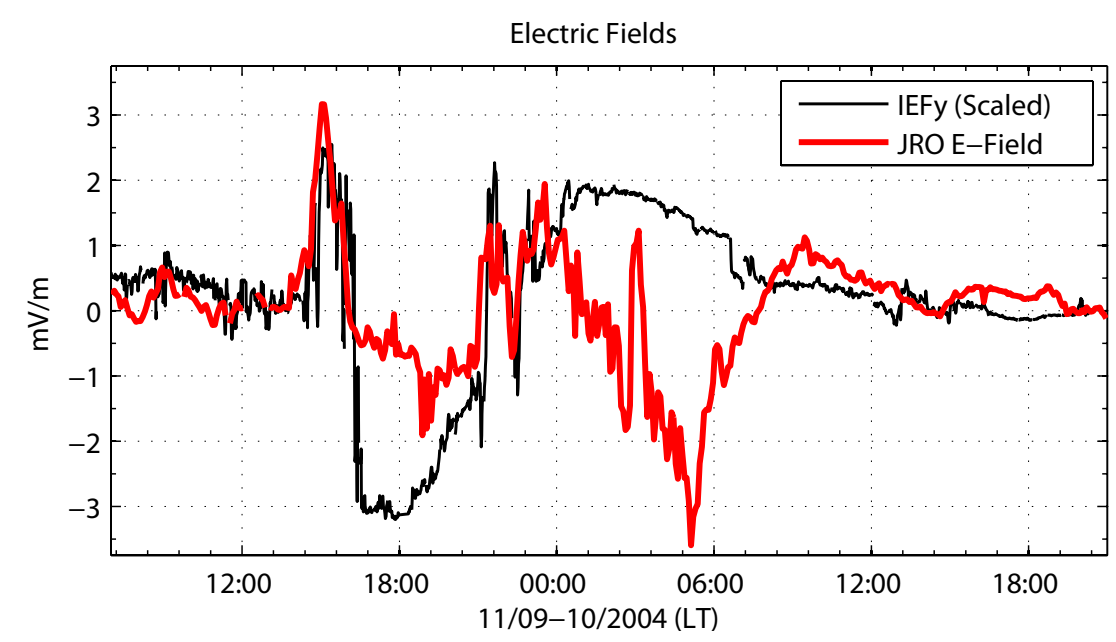

Fig. 1. Electric field measured at Jicamarca with the $\mathrm{IEF}_{y}$ divided by ten (figure courtesy of Ronald Ilma).
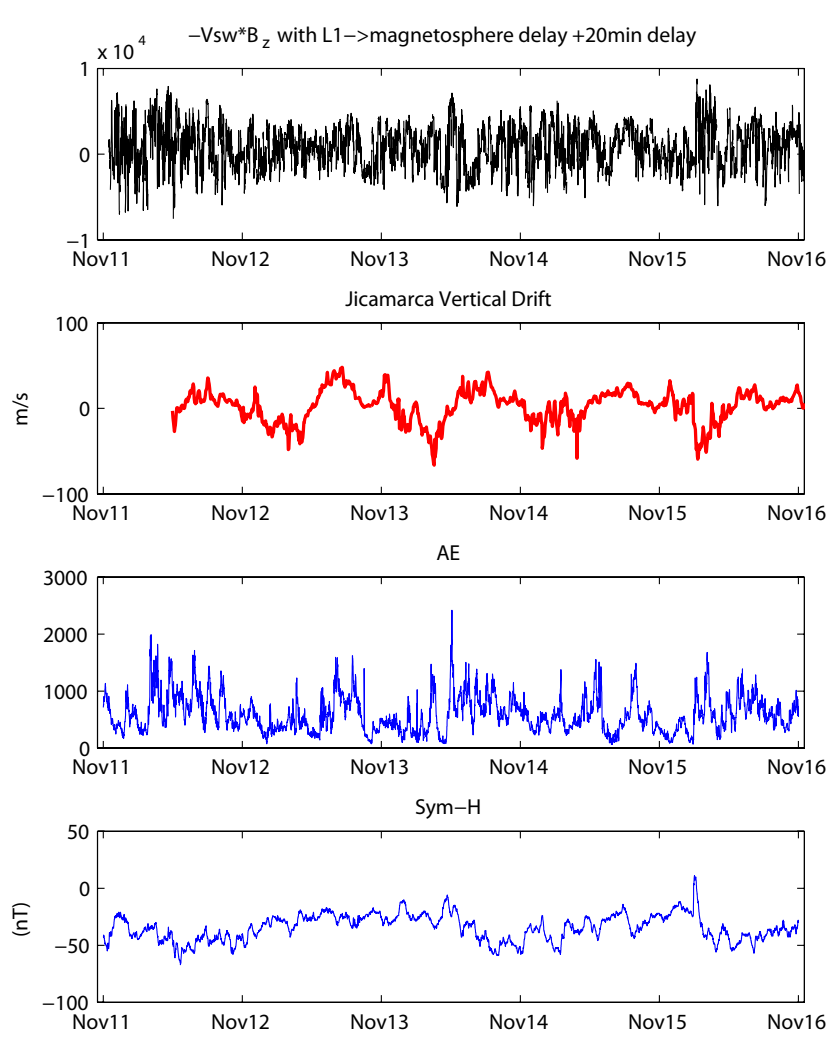

Fig. 2. Coincident measurements by Ace $\left(-V_{s w} \times B_{z}\right)$, Jicamarca vertical drift, AE, and Sym-H.

periods of oscillatory behavior near this frequency, providing an opportunity to explore the local time effect.

To determine any correlation between the y-component of the interplanetary electric field $\left(\mathrm{IEF}_{y}\right)$ recorded by the Advanced Composition Experiment (ACE) satellite and the vertical drift recorded at the Jicamarca Observatory, we must ac- count for two issues: the time delay for the IEF to travel from ACE to Jicamarca, and geophysical noise associated with the neutral wind dynamo.

If penetration occurs, $\mathrm{IEF}_{y}$ signatures observed by the ACE satellite would be observed at Jicamarca with a delay, since time is required to travel between the two points. To first order, the time delay is calculated as:

Delay $=$ Distance Traveled/Velocity of Solar Wind

The distance traveled is roughly $141600 \mathrm{~km}$. Velocities of the solar wind $\left(V_{s w}\right)$ at a given time are readily available from the ACE satellite's readings. Note that there will also be additional lag due to the retardation of the solar wind by the bow shock and transfer of the fields to the geomagnetic tail. Such a delay may range roughly between 10 to $25 \mathrm{~min}$. In Fig. 2, we plot $\operatorname{IEF}_{y}\left(-V_{s w} \times B_{z}\right)$ with the interplanetary time delay plus a nominal 20-min additional delay due to the magnetosphere.

With this compressed format, the IEF data appear to be quite noisy due to high frequency fluctuations that are most likely due to Alfvén waves which, apparently, do not map into the magnetosphere very efficiently.

Theoretical (Vasyliunas, 1972) and experimental (Kelley and Earle, 1987; Kelley et al., 2008) studies indicate that the magnetosphere acts as a bandpass filter with a high pass near $8 \mathrm{~h}$ and a weak resonance near a few hours. In addition, due to the neutral dynamo, the vertical drift observed at Jicamarca picks up a large range of frequencies that we are not interested in. For instance, in the second panel of Fig. 2, there is a very strong diurnal effect that is unrelated to IEF. We thus bandpass filter both data sets to better match the transfer function.

In order to pick our range of desired frequencies, we plotted the power spectrum at Jicamarca using the fast Fourier transform (Fig. 3). We chose to high pass at $2 \times 10^{-5} \mathrm{~Hz}$ in order to filter out the large diurnal components. We chose 

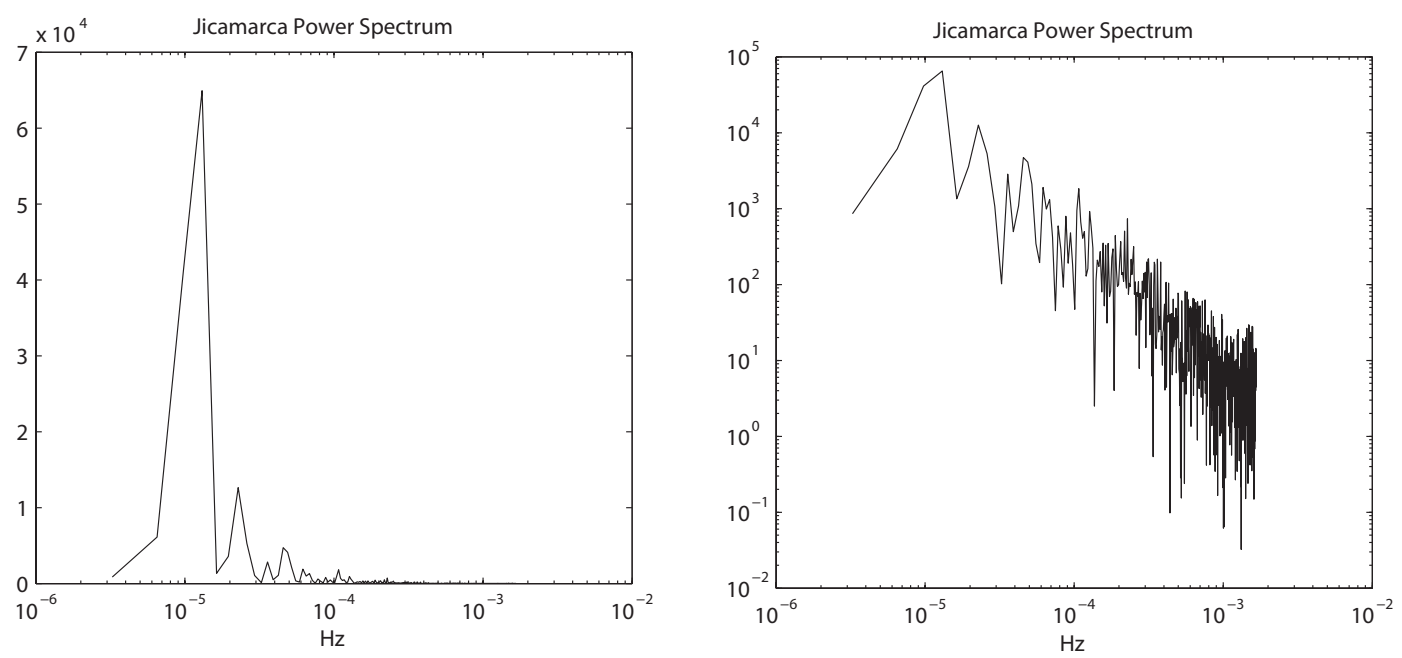

Fig. 3. Linear-log and $\log -\log$ depictions of the Jicamarca data set. We are only interested in frequencies between $2 \times 10^{-5} \mathrm{~Hz}$ and $2 \times 10^{-4} \mathrm{~Hz}$.

to low pass at $2 \times 10^{-4} \mathrm{~Hz}$ to filter out high frequency noise, which does not map. We implement the bandpass filter with Matlab's finite impulse response filter. To avoid phase shifts from filtering, we ran the filter in both the forward and reverse directions. The log-log version of the spectrum shows the dominant diurnal peak and strong second and third harmonics. The latter may be due to a combination of steepening and an 8 -h tide. Since we chose to only analyze frequencies between $2 \times 10^{-5} \mathrm{~Hz}$ and $2 \times 10^{-4} \mathrm{~Hz}$, we also treated the ACE data by applying the same bandpass filtering process. The top two plots in Fig. 4 show clean signals from both the ACE satellite and the Jicamarca Observatory after filtering.

As can be seen from the third panel of Fig. 4, there is an apparent anti-correlation before 12:00 UT and a positive correlation after 12:00 UT. To quantify the correlation at a given hour, we calculated the Pearson correlation coefficient within a window that spans four hours and is centered at that given hour. For instance, we use a window that spans from 07:00 to 11:00 o'clock to calculate the correlation at 09:00 o'clock. The window is advanced one hour in order to generate the plot. The fourth panel in Fig. 4 shows the correlation during 15 November 2003. For this day, as indicated in the upper legend, the highest correlation/anti-correlation occurred for a bow shock/magnetospheric additional delay of $20 \mathrm{~min}$.

The correlation coefficients from 11 November to 15 November 2003 were also calculated and displayed in Fig. 5. Note that, for a given day, we delayed the ACE data by an additional time that maximizes the correlation or anticorrelation. From our data set, this ranged from 15 to $25 \mathrm{~min}$. In this figure, we plot the data versus local time at Jicamarca. One can note the positive correlation during the day and the negative correlation during the night. The period of anti-correlation appears to occur from about 21:00 LT to near 04:00 LT.
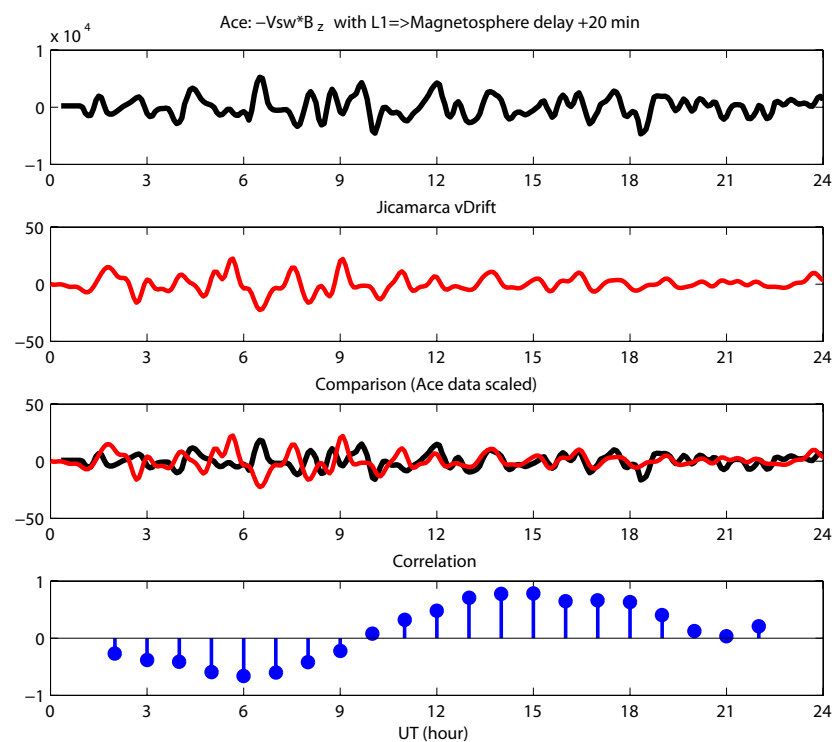

Fig. 4. Comparison of an electric field observed by the ACE satellite and the Jicamarca Observatory during 15 November 2003. Notice an initial anti-correlation and then, later, a positive correlation between IEF $_{y}$ and the electric field observed at Jicamarca.

\section{Conclusion}

At a period of a few hours, the penetration of electric fields of solar wind origin is at its highest efficiency. Here we have isolated a range of frequencies centered at this period for five days and have explored the local time dependence of the penetration, along with the time delay due to magnetospheric effects. We find that the latter ranges from 15 to $25 \mathrm{~min}$. As for the local time dependence, we find that the period of anti-correlation is from 21:00 to 04:00 LT with a positive 

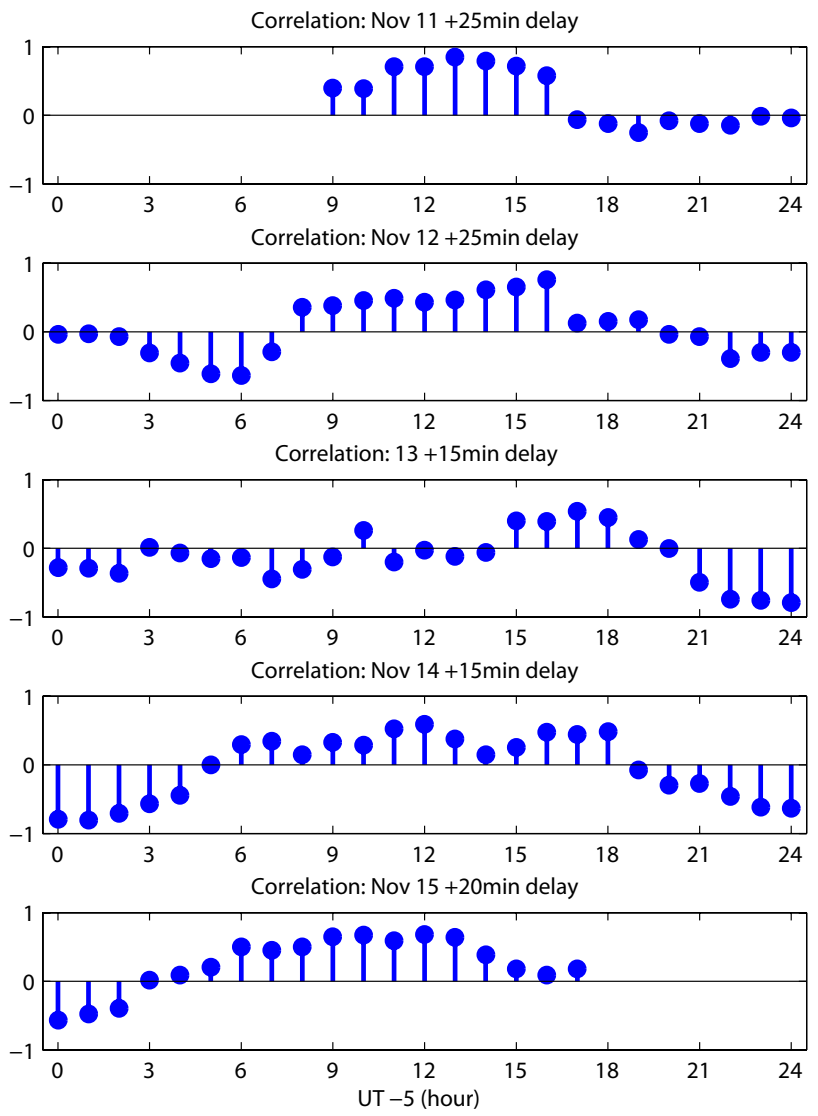

Fig. 5. During the period of 11-15 November 2003, a pattern of correlation appears to exist during the day and anti-correlation at night. Note that the time scale is set to local time at Jicamarca.

correlation at other local times. Note that these statements are equally valid for $B_{z}$ south and north.
Acknowledgements. Work at Cornell University was supported under grant ATM-0551107 from the Atmospheric Science Section of the National Science Foundation, which has a Research Experience for Undergraduates component.

Topical Editor K. Kauristie thanks two anonymous referees for their help in evaluating this paper.

\section{References}

Earle, G. and Kelley, M. C.: Spectral studies of the sources of ionospheric electric fields, J. Geophys. Res., 92, 213-224, 1987.

Gonzales, C. A., Kelley, M. C., Behnke, R. A., Vickery, J. F., Wand, R. H., and Holt, J.: On the latitudinal variations of the ionospheric electric field during magnetospheric disturbances, J. Geophys. Res., 88, 9135-9144, 1983.

Kelley, M. C. and Retterer, J. M.: First successful prediction of a convective equatorial ionospheric storm using solar wind parameters, Space Weather, 6, S08003, doi:10.1029/2007SW000381, 2008.

Kelley, M. C., Fejer, B. G., and Gonzales, C. A.: An explanation for anomalous ionospheric electric fields associated with a northward turning of the interplanetary magnetic field, Geophys. Res. Lett., 6, 301-304, 1979.

Kelley, M. C., Makela, J. J., Chau, J. L., and Nicolls, M. J.: Penetration of the solar wind electric field into the magnetosphere/ionosphere system, Geophys. Res. Lett., 30, 1158, doi:10.1029/2002GL016321, 2003.

Kelley, M. C., Ilma, R. R., Nicolls, M. J., Erickson, P., Goncharenko, L., Chau, J. L., Aponte, N., and Kozyra, J.: Spectacular low and mid-latitude electrical fields and neutral winds during a superstorm, J. Atmos. Solar-Terr. Phys., in press, 2009.

Nishida, A.: Geomagnetic $\mathrm{D}_{P} 2$ fluctuations and associated magnetospheric phenomena, J. Geophys. Res., 73, 1795-1803, 1968.

Nopper, R. W. and Carovillano, R. L.: Polar equatorial coupling during magnetically active periods, Geophys. Res. Lett., 5, 699702, 1978.

Vasyliunas, V. M.: The interrelationship of magnetospheric processes, in: Earth's Magnetospheric Processes, edited by: McCormac, B. M., p. 29, Reidel, Boston, Massachusetts, 1972. 